\title{
Frontières
}

\section{VERGELY, Bertrand, La mort interdite, Paris, JC Lattès, 2001,} 303 p.

\section{Jean-Jacques Lavoie}

Volume 15, numéro 1, automne 2002

URI : https://id.erudit.org/iderudit/1073917ar

DOI : https://doi.org/10.7202/1073917ar

Aller au sommaire du numéro

Éditeur(s)

Université du Québec à Montréal

ISSN

1180-3479 (imprimé)

1916-0976 (numérique)

Découvrir la revue

Citer ce compte rendu

Lavoie, J.-J. (2002). Compte rendu de [VERGELY, Bertrand, La mort interdite, Paris, JC Lattès, 2001, 303 p.] Frontières, 15(1), 80-81.

https://doi.org/10.7202/1073917ar

Ce document est protégé par la loi sur le droit d'auteur. L'utilisation des services d'Érudit (y compris la reproduction) est assujettie à sa politique d'utilisation que vous pouvez consulter en ligne.

https://apropos.erudit.org/fr/usagers/politique-dutilisation/
Cet article est diffusé et préservé par Érudit.

Érudit est un consortium interuniversitaire sans but lucratif composé de l’Université de Montréal, l'Université Laval et l'Université du Québec à Montréal. Il a pour mission la promotion et la valorisation de la recherche. https://www.erudit.org/fr/ 
VERGELY, Bertrand.

\section{La mort interdite}

Paris, JC Lattès, 2001, 303 p.

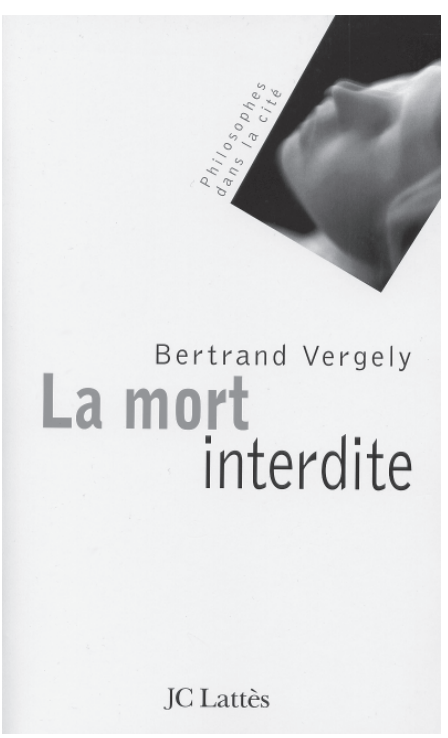

Cet ouvrage part d'une observation fort simple: notre monde est en crise face à la mort (p. 9-42). Le sens de la mort est devenu problématique, le sens de la vie également. Le matérialisme contemporain a émoussé la notion d'altérité, séparant la vie et la mort. II a émoussé cette altérité en imposant trois grandes idées concernant la vie et la mort. La première d'entre elles porte un regard sinistre sur la vie, car elle consiste à dire que la vie est la mort même. La vie n'est-elle pas une lente mort du fait du vieillissement qui la dévore de l'intérieur? La deuxième idée réside dans la croyance que la mort est la vie même. Cette idée, qui s'apparente à une sorte d'euphorie suicidaire, est la suite logique de la première. En effet, quand la vie devient la mort, la mort ne devientelle pas la vie? La troisième idée cherche, elle aussi, à dissoudre la tension vie-mort, mais dans une sorte de pan-dynamisme, car elle consiste à voir dans la vie et la mort les deux termes d'un couple activant I'univers d'une façon éternellement renaissante. Bien que très anciennes, ces trois idées caractérisent la sagesse du monde actuel. En bref, Vergely conclut cette première partie du livre en affirmant que "nous vivons sous la dictature du tragique, qui consiste à priver la mort de tout mystère » (p. 41-42).
Dans la deuxième partie de I'ouvrage (p. 43-113), Vergely analyse trois grandes attitudes face à la mort. La première consiste à en avoir peur; la deuxième consiste à se laisser fasciner par elle et la troisième, qui résulte des deux attitudes précédentes, consiste "à flotter à son égard » (p. 51) et à tomber finalement malade à cause d'elle. Cette analyse est suivie de quelques réflexions polémiques, surtout à l'égard d'André Compte-Sponville et de Michel Onfray, sur les diverses perceptions matérialistes de la mort. Qui connaît ces deux philosophes aura compris que l'athéisme et I'hédonisme constituent les deux principaux thèmes du débat. Puis, abandonnant le ton quelque peu belliqueux, Vergely propose certaines remarques intéressantes sur la mort ludique dans notre société contemporaine. Par divers exemples, comme celui de la vitesse, il montre combien la mort n'est plus le terme de la vie mais le moyen d'un jeu, l'ingrédient essentiel d'une ivresse de l'existence. Reprenant un ton polémique, cette fois-ci particulièrement à l'égard des féministes, il s'interroge ensuite sur le suicide, l'euthanasie et l'avortement. Toutefois, l'interrogation se transforme rapidement en une condamnation de ces pratiques et en une critique du rêve technique de mourir vite, bien et en beauté.

Un peu plus homogène, la troisième partie de l'ouvrage (p. 115-173) est consacrée à la question anthropologique de l'âme. Tout en convoquant la tradition philosophique occidentale et la tradition chrétienne, ou plus précisément la tradition platonico-chrétienne, Vergely rédige une plaidoirie en faveur de l'existence de l'âme comme réalité distincte du corps. Aussi, comme la vision des cadavres est l'un des arguments contre l'âme et son existence, l'auteur termine sa plaidoirie par une longue réflexion sur le cadavre et la "cadavérisation du monde" (p. 144), c'est-à-dire la Shoah. Après quoi, dans la quatrième partie de l'ouvrage (p. 175-235), il poursuit sa réflexion philosophico-anthropologique en interrogeant les angoisses et les désirs des êtres humains face à la mort.

Dans les dernières pages du livre (p. 237-300), Vergely sonde les mystères de la souffrance, du mal et de la mort. Face à ce triple mystère qui défie toute rationalisation, il propose un plaidoyer pour un salut chrétien et pour un retour aux rites mortuaires. 
Au total, I'ouvrage ressemble à un essai trop rapide et manque d'unité. C'est ce dont témoigne, entre autres, l'absence d'une véritable introduction et d'une réelle conclusion. Enfin, comme le laisse percevoir ce bref compte rendu, les sujets abordés par ce livre sont complexes et multiples, tant philosophiques, éthiques que religieux, et demanderaient à être discutés en détail, d'autant plus que sur le fond, l'auteur n'emporte pas toujours l'adhésion.

Jean-Jacques Lavoie 